Check for updates

Cite this: RSC Adv., 2021, 11, 15231

\section{Design of a novel poly(aryl ether nitrile)-based composite ultrafiltration membrane with improved permeability and antifouling performance using zwitterionic modified nano-silica}

\author{
Qi Wang, Fengna Dai, Shangying Zhang, Mengxia Wang, Chunhai Chen \\ and Youhai Yu (DD *
}

\begin{abstract}
Zwitterionic nano-silica $\left(\mathrm{SiO}_{2} \mathrm{NPs}\right)$ obtained by lysine surface modification was used as a hydrophilic inorganic filler for preparing a poly(aryl ether nitrile) (PEN) nanocomposite membrane via an immersion precipitation phase inversion method. The effects of zwitterionic $\mathrm{SiO}_{2} \mathrm{NPs}$ addition on the morphology, separation and antifouling performance of the synthesized membranes were investigated. Zwitterionic surface modification effectively avoided the agglomeration of $\mathrm{SiO}_{2} \mathrm{NPs}$. The PEN/zwitterionic $\mathrm{SiO}_{2} \mathrm{NPs}$ composite membranes exhibited improved porosity, equilibrium water content, hydrophilicity and permeability due to the introduction of hydrophilic $\mathrm{SiO}_{2} \mathrm{NPs}$ in the casting solution, and the optimal pure water flux was up to $507.2 \mathrm{~L} \mathrm{~m}^{-2} \mathrm{~h}^{-1}$, while the BSA rejection ratio was maintained at $97.4 \%$. A static adsorption capacity of $72.9 \mu \mathrm{g} \mathrm{cm}^{-2}$ and the FRR up to $85.3 \%$ in the dynamic antifouling experiment proved that the introduction of zwitterionic $\mathrm{SiO}_{2} \mathrm{NPs}$ inhibited irreversible fouling and enhanced the antifouling ability of the PEN membrane.
\end{abstract}

Received 16th January 2021 Accepted 17th April 2021

DOI: $10.1039 / \mathrm{d} 1 \mathrm{ra00376c}$

rsc.li/rsc-advances electronics, military, and aerospace fields due to its excellent mechanical properties, good thermal stability, excellent radiation resistance, physical and chemical resistance. ${ }^{20-22}$ In recent years, it has also been used to in water treatment. ${ }^{23,24}$ However, due to their inherent hydrophobicity, both PEN and traditional polymeric membrane materials suffer from the problem of membrane fouling. ${ }^{25}$ Thus, the preparation of polymeric membrane with excellent antifouling properties has been a hot topic.

Research shows that during the filtration process, the hydrophilic polymeric membrane is more likely to form hydration layer on the surface, which effectively weakens the interaction between hydrophobic contaminants and membrane surface. Simultaneously, due to the barrier of hydrated layer, the pollutants deposited on the membrane surface is easier to wash off, thereby greatly improving the antifouling performance of the membranes. ${ }^{26-28}$ Several modification methods include blending, ${ }^{29-31}$ coating, ${ }^{32}$ surface grafting ${ }^{33,34}$ and bulk modification, ${ }^{35}$ have been developed to improve the hydrophilicity of the polymeric membranes. Among them, blending, especially the physical blending with hydrophilic nanoparticle materials to prepare mixed matrix membranes (MMMs) with improved hydrophilicity has been wildly adopted due to the advantage of easy operation.

$\mathrm{SiO}_{2} \mathrm{NPs}$, a common inorganic filler with the benefits of nontoxic, long-term stability, high specific surface area and hydrophilicity, has been widely used to adjust the permeability and 
antifouling properties of polymeric membranes. ${ }^{36-38} \mathrm{SiO}_{2} \mathrm{NPs}$ with high specific surface area usually causes particle agglomeration due to their high surface energy, and thus exhibit a poor dispersion stability, which greatly hinders the appearance of their nano-scale material characteristics. ${ }^{39}$ Zwitterionic material refers to an amphoteric polymer with positive and negative charge groups on the same monomer. ${ }^{40}$ Lysine is a cheap, nontoxic, and environmentally friendly zwitterionic amino acid which has excellent hydrophilicity. ${ }^{41}$ For lysine in the zwitterionic state, $\mathrm{H}$ protons in the $-\mathrm{COOH}$ in the non-ionized state are transferred to the $-\mathrm{NH}_{2}$ terminal to form amphoteric ions with both $-\mathrm{NH}^{3+}$ and $-\mathrm{COO}^{-}$. The silane coupling agent $\mathrm{KH} 560$, containing oleophilic epoxy terminal and inorganic silane terminal, is commonly used for $\mathrm{SiO}_{2}$ surface modification. ${ }^{\mathbf{4 2 , 4 3}}$ The inorganic silane terminal can tightly link with $\mathrm{SiO}_{2}$ through dehydration and condensation, while the oleophilic epoxy terminal can bound with specific organics through the ringopening reaction. ${ }^{4,45}$ Using KH560 as a connecting medium, lysine can be grafted onto the $\mathrm{SiO}_{2}$ NPs surface to realize the zwitterionization of nanoparticles. On one hand, since $\mathrm{SiO}_{2}$ surface was coated with zwitterionic long chain, it effectively weakened the hydrogen bonding between the adjacent $-\mathrm{OH}$ on the nanoparticles surface, and also generated steric hindrance, which ultimately reduced the agglomeration between nanoparticles. ${ }^{46}$ On the other hand, due to the strong solvation and hydrogen bonding characteristics of the zwitterionic chain end groups, it is more conducive to the formation of a dense hydration layer on the surface, thus reducing the non-specific adsorption with proteins. ${ }^{47,48}$

In this work, lysine was used as a surface modifier for the preparation of zwitterionic $\mathrm{SiO}_{2}$ NPs to promote the dispersion stability and hydrophilicity of nanoparticles in the casting solution system. ${ }^{49}$ PEN flat sheet composite membranes with different concentration of zwitterionic $\mathrm{SiO}_{2}$ NPs were prepared by immersion precipitation phase inversion method with PVPk30 as pore-forming agent and a mixture of DMAc and NMP as solvent. The effects of zwitterionic $\mathrm{SiO}_{2} \mathrm{NPs}$ addition on the morphology, separation and antifouling performance of the synthesized membranes were investigated in detail.

\section{Experimental}

\subsection{Materials}

PEN $\left([\eta]=1.15 \mathrm{dL} \mathrm{g}^{-1}\right)$ synthesized in the laboratory as described in previous literature ${ }^{50}$ was used as the base polymer in the casting solution. Reagent grade PVP-k30 supplied by Macklin Biochemical Technology Co. Ltd. was used as poreforming agent. The chemical structure of PEN and PVP were shown in Fig. 1. Reagent grade DMAc ( $\geq 99.8 \%$ purity) and NMP ( $\geq 99.5 \%$ purity) supplied by Macklin, were used as mixed solvent without further purification. $\mathrm{SiO}_{2} \mathrm{NPs}$ (7-40 nm, hydrophilic-380 type) and 3-glycidyloxypropyl (dimethoxy) methylsilane (GPMS, KH560) were obtained from Aladdin Biochemical Technology Co. Ltd. Lysine, Hydrochloric acid, Ethanol were purchased from Sinopharm Group Chemical Reagent Co. Ltd. Bovine serum albumin (BSA) with molecular weight of 68000 Da was obtained from Energy Chemical Co.

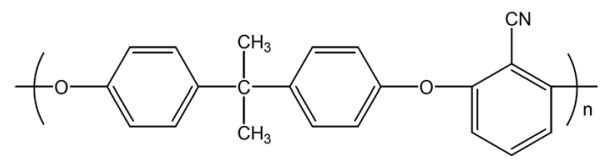

Poly (aryl ether nitrile)

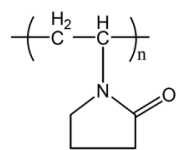

Polyvinylpyrrolidone

Fig. 1 Molecular structure of poly(aryl ether nitrile) and polyvinylpyrrolidone.

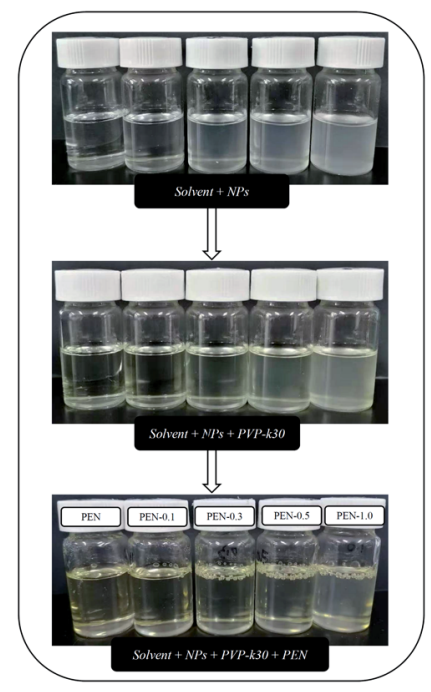

Fig. 2 The real situation of the casting solution in different states.

Ltd. Deionized water purified with Millipore system (Millipore, France) was used as the coagulation bath.

\subsection{Surface modification of nano-silica}

Surface modification of $\mathrm{SiO}_{2}$ NPs was performed to overcome agglomeration and improved its dispersion. Firstly, $1.0 \mathrm{~g} \mathrm{\textrm {SiO } _ { 2 }}$ NPs were dispersed into a $50 \mathrm{~mL}(20 \%, \mathrm{v} / \mathrm{v})$ ethanol aqueous solution by ultrasound for $0.5 \mathrm{~h}$. Then, $0.3 \mathrm{~g}$ GPMS and several drops of hydrochloric acid were added into the solution to react with a magnetic stirring at $60{ }^{\circ} \mathrm{C}$ for $6 \mathrm{~h}$. Subsequently, $5 \mathrm{~mL}$ $\left(10 \%, \mathrm{~g} \mathrm{~g}^{-1}\right)$ lysine aqueous solution was added into the above solution to keep reaction for another $3 \mathrm{~h}$. Finally, the modified nano- $\mathrm{SiO}_{2}$ was washed several times to neutrality by centrifugation with ethanol, and then thoroughly dried in a vacuum oven at $80^{\circ} \mathrm{C}$ for use.

\subsection{Preparation of PEN nanocomposite membranes}

PEN nanocomposite membranes were prepared by immersion precipitation phase inversion method. Firstly, a certain amount of zwitterionic $\mathrm{SiO}_{2}$ NPs was dispersed in a mixed solvent of 
Table 1 Composition of the casting solution and their viscosities

\begin{tabular}{|c|c|c|c|c|c|}
\hline Membranes & $\begin{array}{l}\text { Polymer (wt\%) } \\
\text { PEN }\end{array}$ & $\begin{array}{l}\text { Pore-forming agent } \\
\text { (wt\%) PVP-k30 }\end{array}$ & $\begin{array}{l}\text { Nanoparticles (wt\%) } \\
\text { zwitterionic } \mathrm{SiO}_{2}\end{array}$ & $\begin{array}{l}\text { Solvent }(\mathrm{wt} \%) \\
\text { DMAc }: \mathrm{NMP}=4: 1\end{array}$ & $\begin{array}{l}\text { Suspension viscosity, } \\
\text { (cP) }\end{array}$ \\
\hline Pristine PEN & 16 & 8 & 0.0 & 76.0 & 18479 \\
\hline PEN-0.1 & 16 & 8 & 0.1 & 75.9 & 18823 \\
\hline PEN-0.3 & 16 & 8 & 0.3 & 75.7 & 19576 \\
\hline PEN-0.5 & 16 & 8 & 0.5 & 75.5 & 20382 \\
\hline PEN-1.0 & 16 & 8 & 1.0 & 75.0 & 21268 \\
\hline
\end{tabular}

DMAc and NMP through ultrasonication for $3 \mathrm{~h}$ to obtain a stable dispersion while more than $1 \mathrm{wt} \%$ of $\mathrm{SiO}_{2}$ NPs would lead to a poor dispersion stability in the solvent. Then, $8 \mathrm{wt} \%$ of PVP-k30 was dissolved by stirring. Subsequently, $16 \mathrm{wt} \%$ of PEN was added and completely dissolved to form a uniform solution by continuous stirring at $60{ }^{\circ} \mathrm{C}$. The real situation of each casting solution in different states were shown in Fig. 2. Furthermore, defoaming was performed for $0.5 \mathrm{~h}$ to remove air bubbles. Finally, the casting solution was spread uniformly on a clean glass plate with the help of a casting knife maintaining a clearance of approximately $100 \mu \mathrm{m}$ between the knife and glass plate at room temperature and relative humidity $\leq 50 \%$. The prepared membrane was then exposed for about $25 \mathrm{~s}$ in ambient before immersion into the coagulation bath of deionized water (DI water). The casted films changed color from transparent to white immediately and separated out of the glass after a while. Then, the prepared membrane was kept and saved in DI water for a complete liquid-liquid separation. Finally, the flat sheet membranes were cut into a rectangle $(8.50 \mathrm{~cm} \times 3.50$ $\mathrm{cm})$ to place inside the membrane cell. All samples were visually inspected for defects and used for membrane evaluation.

Membranes with different concentration of zwitterionic nano-SiO ${ }_{2}$ were designated as Pristine PEN, PEN-0.1, PEN-0.3, PEN-0.5 and PEN-1.0. Table 1 represented the composition and viscosities of each casting solution. The concentration of PEN kept constant at $16 \mathrm{wt} \%$, while PVP-k30 kept at $8 \mathrm{wt} \%$, DMAc : NMP $=4: 1$ as a mixed solvent.

\subsection{Characterization of zwitterionic nano-silica}

The particle size distribution and zeta potential before and after the modification of nano-SiO ${ }_{2}$ was tested by the zeta-potential analysis and particle size analyzer (Nano ZS, Malvern). The chemical compositions of nanoparticles were characterized by Fourier transform infrared spectroscopy (FTIR, VERTEX70) at a scanning range of $400-4000 \mathrm{~cm}^{-1}$, and X-ray photoelectron spectroscopy (XPS, Escalab 250Xi). The dispersion stability of nano-SiO $\mathrm{S}_{2}$ before and after modification in water was assessed by natural gravimetric sedimentation over a period of time in static mode.

\subsection{Characterization of membrane}

The surface and cross-section morphology of resulting membranes were observed by a field emission scanning electron microscope (SEM, *Regulus8230) with energy dispersive Xray spectroscopy (EDX). All specimens were freeze-dried and coated with a thin layer of gold before observation. Cross- section was prepared by fracturing membrane in liquid nitrogen.

The surface morphology (2D and 3D topographic images) and roughness analysis of mean roughness $\left(R_{\mathrm{a}}\right)$ and the root mean square of data $\left(R_{\mathrm{q}}\right)$ for each nanocomposite membrane in a scan area of $5 \mu \mathrm{m} \times 5 \mu \mathrm{m}$ were characterized using an atomic force microscope (AFM, *MFP-3D Bio) at the acoustic AC tapping mode.

Equilibrium water content (EWC) and porosity $(\varepsilon)$ were calculated by the gravimetric method as follows:

$$
\begin{gathered}
\operatorname{EWC}(\%)=\left(W_{\mathrm{w}}-W_{\mathrm{d}}\right) / W_{\mathrm{w}} \times 100 \% \\
\varepsilon(\%)=\left(W_{\mathrm{w}}-W_{\mathrm{d}}\right) / \rho_{\mathrm{w}} A l \times 100 \%
\end{gathered}
$$

where, $W_{\mathrm{w}}$ and $W_{\mathrm{d}}$ is weight of membranes in a wet and dry state (g). $\rho_{\mathrm{w}}, A$, and $l$ are the density of pure water $\left(0.998 \mathrm{~g} \mathrm{~cm}^{-3}\right)$, effective membrane surface area $\left(\mathrm{cm}^{2}\right)$, and membrane thickness $(\mathrm{cm})$, respectively.

The mean pore radius $\left(r_{\mathrm{m}}\right)$ for blended membranes were calculated using the Guerout-Elford-Ferry equation:

$$
r_{\mathrm{m}}=\sqrt{\left[(2.9-1.75 \varepsilon) \times 8 \eta l J_{\mathrm{w}}\right] /(\varepsilon \Delta P)}
$$

where, $\varepsilon$ is porosity of the membrane, $\eta$ is the viscosity of water $\left(8.9 \times 10^{-4} \mathrm{~Pa} \mathrm{~s}\right), l$ is the mean thickness of membrane, $J_{\mathrm{w}}$ is the pure water flux, and $\Delta P$ is the operating pressure $(0.1 \mathrm{MPa})$.

The water contact angle (WCA) of membranes was measured using a Drop Shape Analysis Data physics (OCA 20) at room temperature. The water droplet of $2 \mu \mathrm{L}$ was dropped on membrane surface using motorized controlled micro-syringe. The image of water droplet on membrane surface was captured and surface water contact angle was measured by using imaging software. The contact angle was measured at lots of random points on membrane surface and reported value was the average of these measurements.

The surface energy parameters $\left(\gamma_{\mathrm{s}}\right)$ of the membrane were determined by the Lifshitz-van der Waals $\left(\gamma_{\mathrm{s}}^{\mathrm{LW}}\right)$ and Lewis acidbase $\left(\gamma_{\mathrm{s}}^{\mathrm{AB}}\right)$ (comprising electron-donor $\gamma_{\mathrm{s}}^{-}$and electron-acceptor $\gamma_{\mathrm{s}}^{+}$) was determined with eqn (4).

$$
\gamma_{\mathrm{s}}=\gamma_{\mathrm{s}}^{\mathrm{LW}}+\gamma_{\mathrm{s}}^{\mathrm{AB}}=\gamma_{\mathrm{s}}^{\mathrm{LW}}+2 \sqrt{\gamma_{\mathrm{s}}^{-} \times \gamma_{\mathrm{s}}^{+}}
$$

Contact angle measurements were performed using three different types of probe liquids with known surface energy, in which the water and formamide represent polar liquids, the diiodomethane is a nonpolar liquid. And then, $\gamma_{\mathrm{s}}$ was calculated by solving a set of extended Young-Dupré eqn (5). 


$$
(1+\cos \theta) \gamma_{\mathrm{L}}=2\left(\sqrt{\gamma_{\mathrm{s}}^{\mathrm{LW}} \times \gamma_{\mathrm{L}}^{\mathrm{LW}}}+\sqrt{\gamma_{\mathrm{s}}^{+} \times \gamma_{\mathrm{L}}^{-}}+\sqrt{\gamma_{\mathrm{s}}^{-} \times \gamma_{\mathrm{L}}^{+}}\right)
$$

where, $\theta$ represents the contact angle of the liquid on a solid surface, and subscripts $S$ and $L$ represent the solid surface and the liquid surface, respectively.

\subsection{Ultrafiltration experiments}

The batch experiments were conducted in a crossflow filter (FMT FlowMem-0002). Inside the cell, a rectangular membrane was placed over a base support, the effective filtration area of the membrane was $20 \mathrm{~cm}^{2}$. Under the pressure of the diaphragm pump, the permeate was collected from the bottom of the cell. The schematic of batch experimental was presented in Fig. 3.

Fresh membranes need to be compacted with pure water for $0.5 \mathrm{~h}$ at a transmembrane pressure of $0.2 \mathrm{MPa}$. This pressure is twice than normal operating pressure, which helps to improve the mechanical strength of the membrane and obtain stable water flux. Under the pressure of $0.1 \mathrm{MPa}$, the pure water flux (PWF) and hydraulic permeability $\left(P_{\mathrm{m}}\right)$ were calculated, using the following equations:

$$
\begin{gathered}
J_{\mathrm{w}}=Q /(A \times \Delta T) \\
P_{\mathrm{m}}=J_{\mathrm{w}} / \Delta p
\end{gathered}
$$

where, $J_{\mathrm{w}}$ is pure water flux $\left(\mathrm{L} \mathrm{m}^{-2} \mathrm{~h}^{-1}\right), Q$ is volume of water permeated (L), $A$ is effective membrane area $\left(\mathrm{m}^{2}\right)$ and $\Delta T$ is sampling time $(\mathrm{h}) . P_{\mathrm{m}}$ is hydraulic permeability $\left(\mathrm{L} \mathrm{m}^{-2} \mathrm{~h}^{-1}\right.$ $\left.\mathrm{kPa}^{-1}\right) ; \Delta P$ is transmembrane pressure $(\mathrm{kPa})$.

Followed by pure water flux measurement, the DI water was replaced with model protein solution $\left(1000 \mathrm{mg} \mathrm{L}^{-1}\right.$ of BSA in phosphate buffer solution, $\mathrm{pH}=7.4$ ) to evaluate the rejection ratios of membranes. Percentage rejection of BSA was calculated using the following equation:

$$
R(\%)=\left(1-C_{\mathrm{p}} / C_{\mathrm{f}}\right) \times 100 \%
$$

where, $C_{\mathrm{p}}$ and $C_{\mathrm{f}}$ are the concentrations in the permeate and feed $\left(\mathrm{mg} \mathrm{L}^{-1}\right)$, respectively. The BSA concentration in the permeate was determined using a UV-vis spectrophotometer (PerkinElmer Precisely, Lambda950) at a wave length of $278.5 \mathrm{~nm}$.

\subsection{Antifouling test}

The antifouling ability of separation membrane was usually evaluated by static adsorption and dynamic antifouling experiment of common pollutants. The static adsorption test was carried out by immersing membrane $\left(2 \times 2 \mathrm{~cm}^{2}\right)$ in a BSA solution (1000 $\mathrm{mg} \mathrm{L}^{-1}, \mathrm{pH}=7.4$ ) without additional pressure assisted pollutant into the membrane pore. After adsorptiondesorption equilibrium for $24 \mathrm{~h}$ at room temperature, the concentrations of BSA solution before and after adsorption were measured with a UV-vis spectrophotometer (PerkinElmer Precisely, Lambda 950), and the adsorption mass $Q\left(\mu \mathrm{g} \mathrm{cm}^{-2}\right)$ of

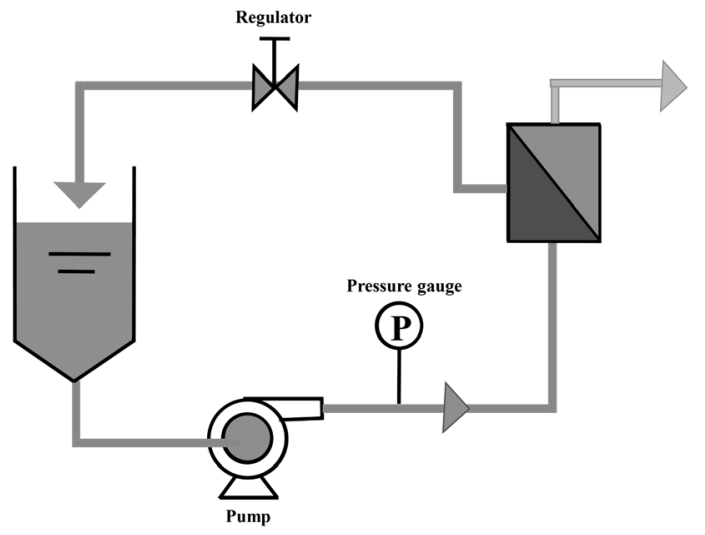

Fig. 3 Schematic of the experimental set-up.

BSA on membrane surface was calculated using the following equation:

$$
Q=\left(C_{0}-C\right) V / S \times 100 \%
$$

where, $C_{0}$ and $C$ are the concentration of BSA solution before and after adsorption ( $\left.\mathrm{mg} \mathrm{L}^{-1}\right)$, respectively, $V$ is the volume of BSA solution (L), $S$ is the adsorption membrane area $\left(\mathrm{cm}^{2}\right)$.

The dynamic fouling experiment was conducted using three cycles of alternating feeding of pure water and pollutants solution. The specific operations of three processes in a cycle are as follows: firstly, under the driving pressure of $0.1 \mathrm{MPa}$, the pure water flux $\left(F_{\mathrm{w} 1}\right)$ of compacted membrane was measured for $45 \mathrm{~min}$. Then followed by $1 \mathrm{mg} \mathrm{mL}{ }^{-1}$ BSA solution as feed for another $45 \mathrm{~min}$, the stable permeation flux was recorded as $F_{\mathrm{p}}$. After that, the membrane was washed and backwashed with pure water for $20 \mathrm{~min}$ to completely remove the effects of reversible fouling. Finally, measure the pure water flux $\left(F_{\mathrm{w} 2}\right)$ again within $45 \mathrm{~min}$. Three cycles of antifouling test for each membrane were conducted. The total fouling ratio $\left(R_{\mathrm{t}}\right)$, reversible fouling $\left(R_{\mathrm{r}}\right)$, irreversible fouling $\left(R_{\mathrm{ir}}\right)$ and flux recovery ratio (FRR) were calculated using eqn (10)-(13), respectively:

$$
\begin{gathered}
R_{\mathrm{t}}(\%)=\left(1-F_{\mathrm{p}} / F_{\mathrm{w} 1}\right) \times 100 \% \\
R_{\mathrm{r}}(\%)=\left[\left(F_{\mathrm{w} 2}-F_{\mathrm{p}}\right) / F_{\mathrm{w} 1}\right] \times 100 \% \\
R_{\mathrm{ir}}(\%)=\left[\left(F_{\mathrm{w} 1}-F_{\mathrm{w} 2}\right) / F_{\mathrm{w} 1}\right] \times 100 \% \\
\text { FRR }(\%)=F_{\mathrm{w} 2} / F_{\mathrm{w} 1} \times 100 \%
\end{gathered}
$$

where, $F_{\mathrm{w} 1}$ is the pure water flux, $F_{\mathrm{p}}$ is the permeation flux of BSA solution, and $F_{\mathrm{w} 2}$ is pure water flux of cleaned membrane (L $\left.\mathrm{m}^{-2} \mathrm{~h}^{-1}\right)$.

\subsection{Mechanical performance test}

Ultrafiltration is a pressure-driven process, the mechanical strength of nanocomposite membrane was measured including breaking strength and elongation at break, using Universal testing machine (Instron USA, capacity: $10 \mathrm{kN}$ ). For each measurement, the sample of $30 \mathrm{~mm}$ length and $5 \mathrm{~mm}$ width was 
used. All the tensile tests were carried out on dry membranes with stretching rate of $1 \mathrm{~mm} \mathrm{~min}^{-1}$ at room temperature.

\section{Results and discussion}

\subsection{Preparation and characterization of zwitterionic nano- silica}

The schematic diagram of the reaction principle of modified nano- $\mathrm{SiO}_{2}$ by lysine zwitterionic material was shown in Fig. 4.

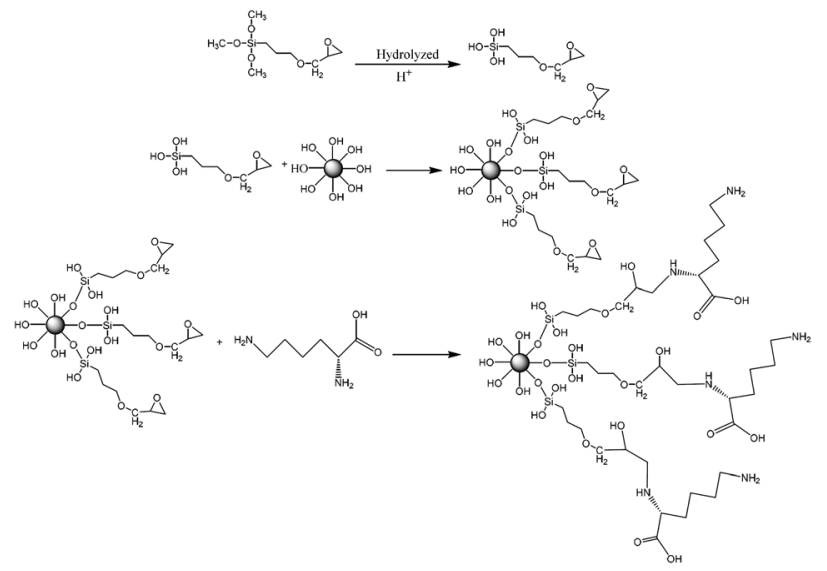

Fig. 4 Schematic diagram of nano- $\mathrm{SiO}_{2}$ zwitterionic modification.
Firstly, the KH560 hydrolyzed under acidic conditions rapidly dehydrated and condensed with hydroxyl groups on the surface of $\mathrm{SiO}_{2}$ to form an intermediate product with active epoxy groups. Subsequently, the ring-opening polymerization between the active amino group on the lysine molecular chain and the epoxy group on the surface of $\mathrm{SiO}_{2}$ was used to graft lysine with a pair of amino and carboxyl functional groups to the surface of the silica nanoparticles. ${ }^{51}$

FTIR spectra of nano-SiO ${ }_{2}$ before and after lysine modification were shown in Fig. 5a. The typical absorption peaks for $\mathrm{SiO}_{2}$ at $1106 \mathrm{~cm}^{-1}, 970 \mathrm{~cm}^{-1}$ and $806 \mathrm{~cm}^{-1}$ could be seen in both spectra, which were attributed to the asymmetric and symmetric stretching vibration of $\mathrm{Si}-\mathrm{O}-\mathrm{Si}$ and the $\mathrm{Si}-\mathrm{OH}$ bending vibration, respectively. Three new peaks at $2940 \mathrm{~cm}^{-1}$, $1508 \mathrm{~cm}^{-1}, 1409 \mathrm{~cm}^{-1}$ appeared on the modified nano-SiO spectrum were belong to the methylene stretching vibration peak, amino shear vibration peak, and carboxyl $\mathrm{OH}$ bond plane bending vibration peak. The characteristic element $\mathrm{N}$ of lysine could be detected in the XPS spectrum of modified $\mathrm{SiO}_{2}$ nanoparticles as shown in Fig. 5b. All these results proved the successful preparation of zwitterionic nano-SiO ${ }_{2}$.

In order to study the effect of zwitterionic modification on the agglomeration of nano- $\mathrm{SiO}_{2}$ particles, the dispersion stability of the $1 \mathrm{mg} \mathrm{mL}{ }^{-1}$ nano-SiO 2 aqueous suspension before and after modification in static mode was evaluated by natural gravimetric
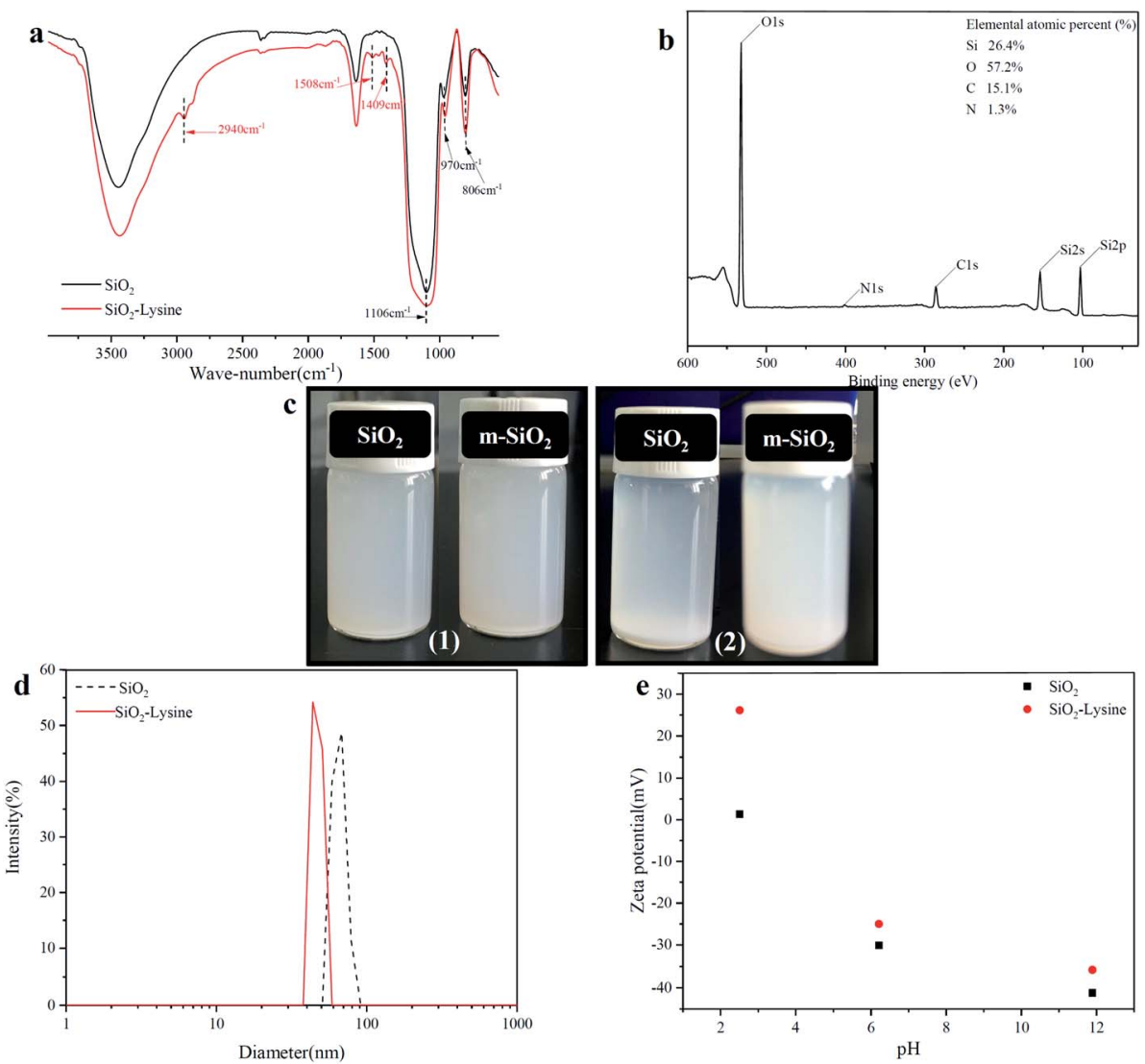

Fig. 5 Characterization of pristine and lysine modified nano- $\mathrm{SiO}_{2}$ [(a) FTIR, (b) XPS of zwitterionic nano-SiO ${ }_{2}$ (c) dispersion stability in water (1) just after 30 min sonication; (2) after $8 \mathrm{~h}$, (d) particle size, (e) zeta potential]. 
(a)

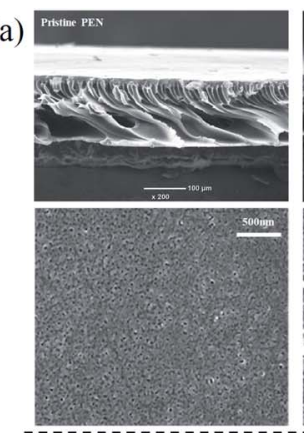

(b)

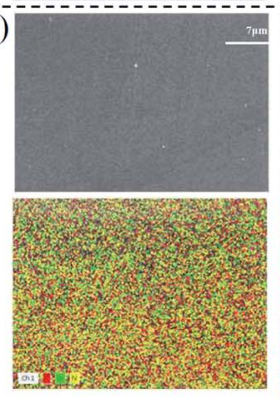

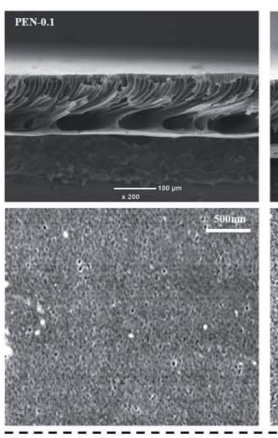
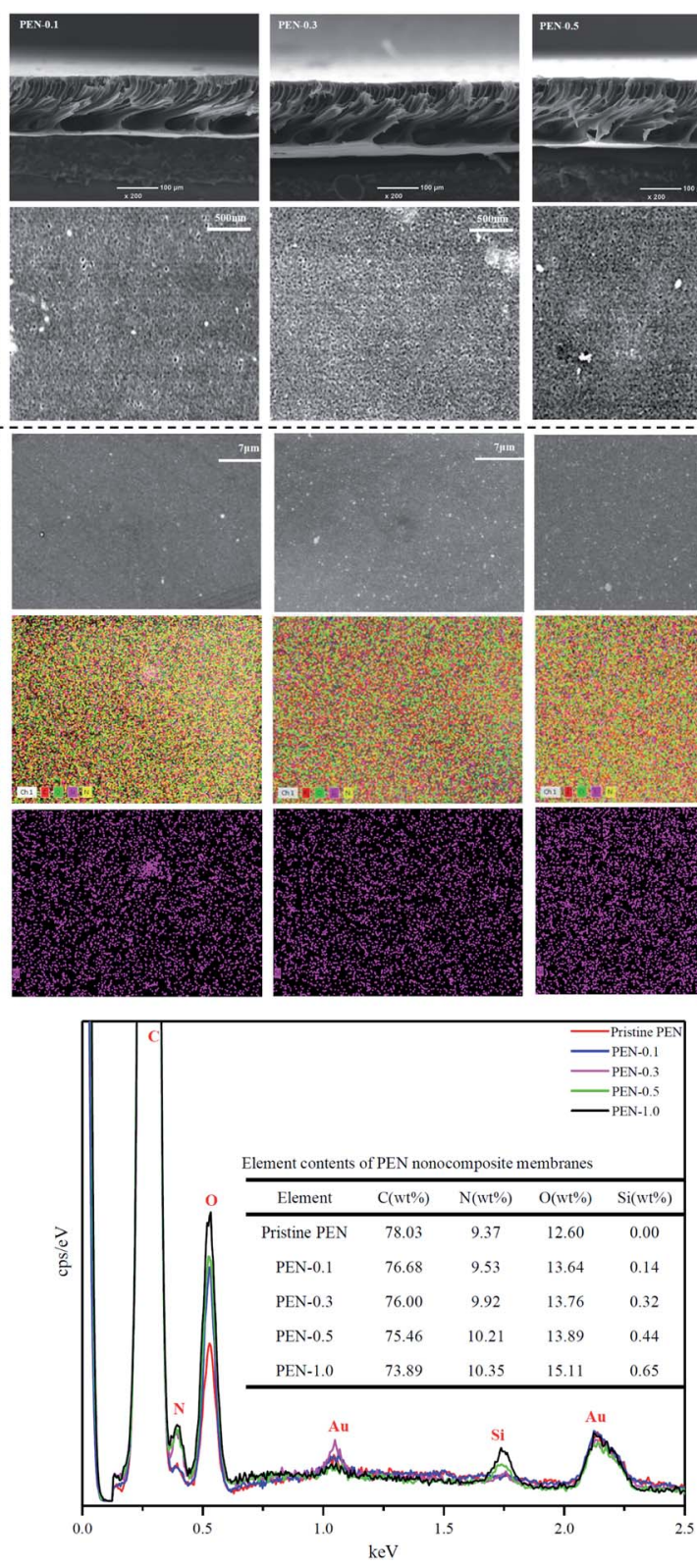
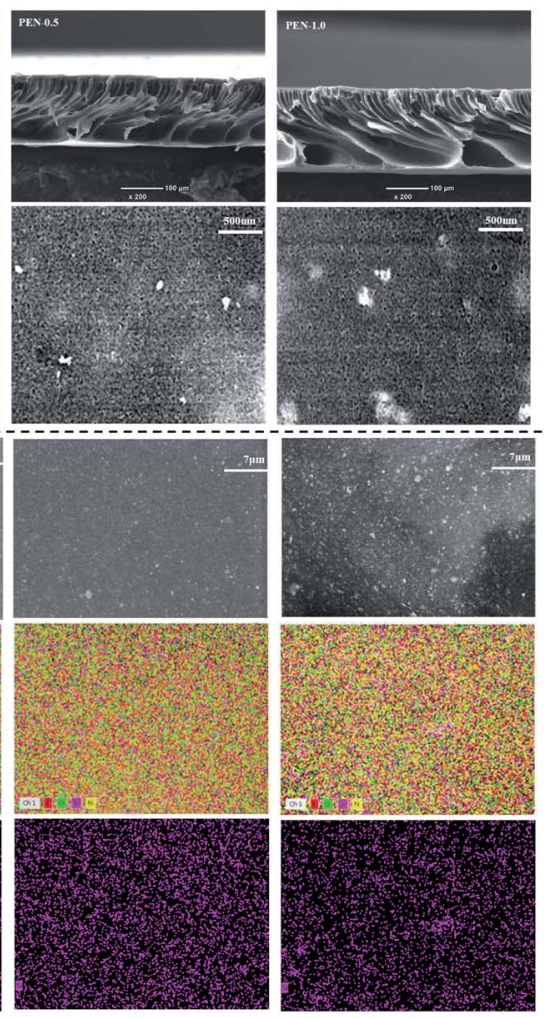

Fig. 6 (a) SEM images of cross-section and top surface (air-side) morphology; (b) EDX of the nanocomposite membranes.

sedimentation and the particle size distribution change of nano$\mathrm{SiO}_{2}$ was measured and the results are shown in Fig. $5 \mathrm{c}$ and $\mathrm{d}$. The nano-SiO ${ }_{2}$ before and after zwitterionic modification can obtain a uniformly dispersed suspension after 30 minutes of ultrasound. After $8 \mathrm{~h}$, the pristine nano- $\mathrm{SiO}_{2}$ particle agglomerated and precipitated, while zwitterionic nano- $\mathrm{SiO}_{2}$ still maintained good dispersion stability. Also, the average size of $\mathrm{SiO}_{2}$ nanoparticles is reduced from the original 66 to $47 \mathrm{~nm}$ after modification. This can be explained that ionogenic pair of amino and carboxyl groups introduced by the zwitterionization of $\mathrm{SiO}_{2}$ NPs reduced the absolute value of nanoparticles surface charge, leading to a better dispersion effect. ${ }^{49}$ Therefore, zwitterionic modification of $\mathrm{SiO}_{2}$ can improve its dispersibility in solution. The change of zeta potential before and after modification of $\mathrm{SiO}_{2}$ nanoparticles at different $\mathrm{pH}$ was shown in Fig. 5e. Compared with the pristine nano- $\mathrm{SiO}_{2}$, lysine modified nano- $\mathrm{SiO}_{2}$ was positively charged but showed a negative charge in a high $\mathrm{pH}$ environment, which is the salient feature of zwitterionic materials.

\subsection{Viscosity of the casting solution}

The relationship between the suspension viscosity and zwitterionic nano- $\mathrm{SiO}_{2}$ concentration has been listed in Table 1 , the apparent viscosity of the casting solution gradually increased with increasing zwitterionic nano-SiO ${ }_{2}$ content. The increasing viscosity of the casting solution can be mainly attributed to the interaction between the polymer molecular chains and the hydroxyl groups enriched on surface of the modified silica nanoparticles with high specific surface area and surface energy. ${ }^{52,53}$ 

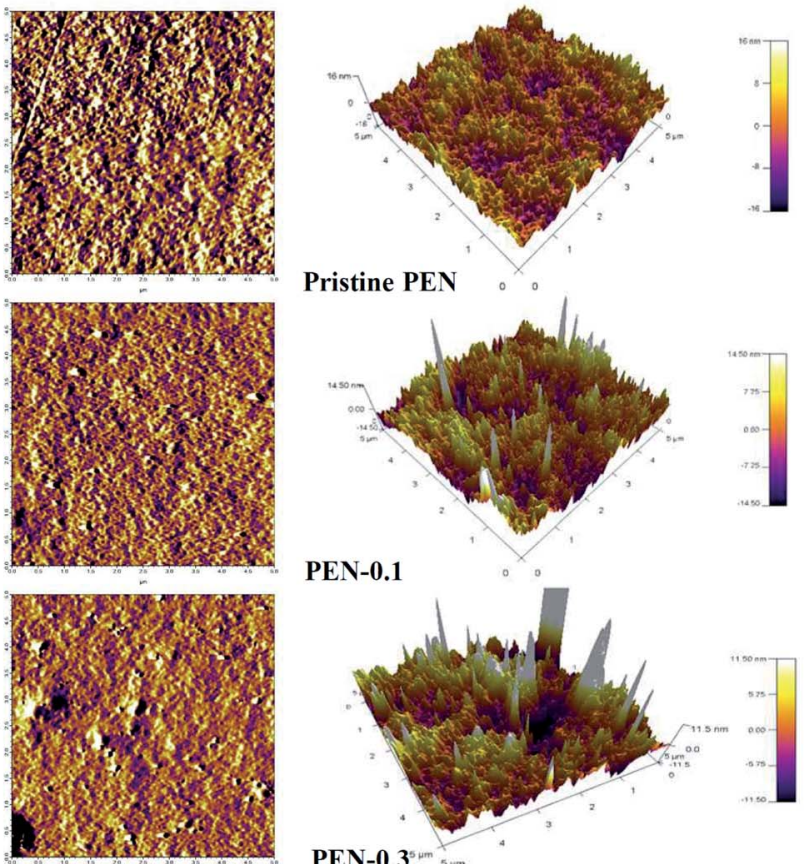

PEN-0.1
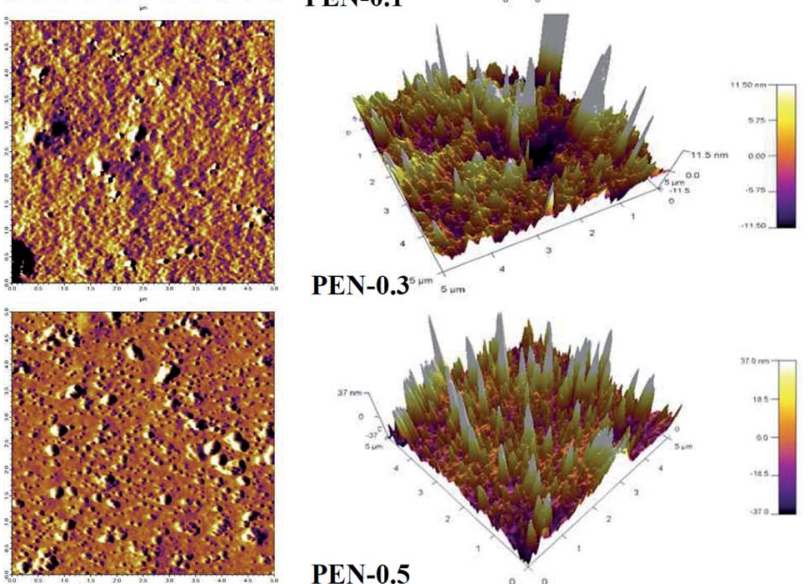

PEN-0.3
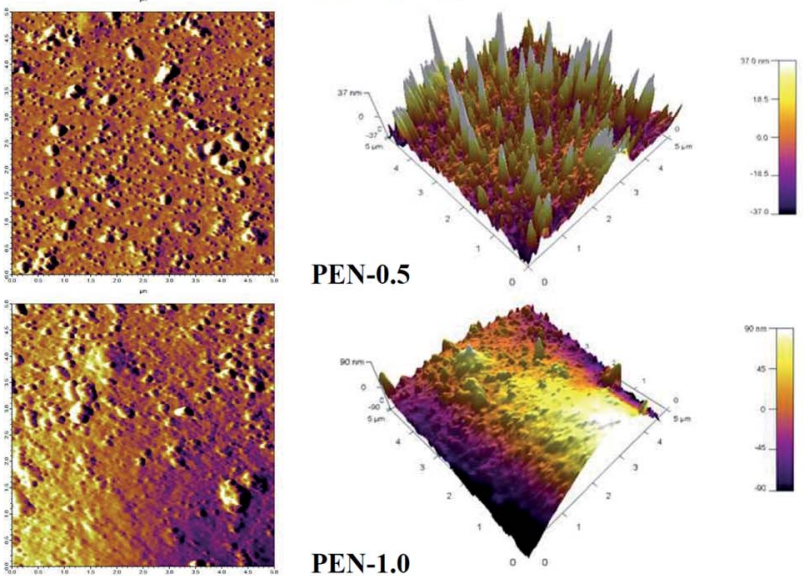

PEN-1.0

Fig. 7 AFM 2D and 3D images of PEN and zwitterionic nano- $\mathrm{SiO}_{2} / \mathrm{PEN}$ nanocomposite membranes.

Table 2 Structural parameters of pristine PEN and nanocomposite membranes

\begin{tabular}{llllll}
\hline & \multicolumn{5}{l}{ Structure parameters } \\
\cline { 2 - 6 } Membranes & $R_{\mathrm{q}}(\mathrm{nm})$ & $R_{a}(\mathrm{~nm})$ & EWC $(\%)$ & $\varepsilon(\%)$ & $r_{\mathrm{m}}(\mathrm{nm})$ \\
\hline Pristine PEN & 3.6 & 2.9 & 73.7 & 66.5 & 42.7 \\
PEN-0.1 & 5.0 & 3.9 & 75.2 & 68.5 & 45.6 \\
PEN-0.3 & 9.7 & 5.1 & 79.6 & 72.8 & 47.6 \\
PEN-0.5 & 14.1 & 9.9 & 83.0 & 76.1 & 52.1 \\
PEN-1.0 & 45.0 & 35.3 & 81.8 & 69.1 & 45.5
\end{tabular}

\subsection{Membrane morphology and structure characterization}

The cross-sectional and top surface morphologies of the pristine $\mathrm{PEN}$ and $\mathrm{PEN}_{-} \mathrm{SiO}_{2}$ nanocomposite membranes were observed by Fig. 6a. A typical asymmetric structure with a dense skin and a finger-like cavity of the sublayer could be observed from the cross-section morphology in both pristine PEN membrane and silica hybrid membranes. The result showed that when the addition of $\mathrm{SiO}_{2}$ was $\leq 1 \mathrm{wt} \%$, there was no significant effect on the structure of membrane sublayer. The observed behavior was consistent with the results reported in the literature. ${ }^{54,55}$ In a higher magnification surface electron micrograph, the micropores on the prepared nanocomposite membrane surface were clearly visible and evenly distributed, thus playing the role of sieving for permeation separation. Actually, when the addition of nanoparticles reached $1 \mathrm{wt} \%$, the agglomeration of nanoparticles on the membrane surface was more obvious, and the defects were more likely to be observed at the edges of the agglomerated nanoparticles. This could be interpreted in accordance with the previous literature as the interface tension between organic phase and inorganic phase caused by the contraction of organic phase during phase separation process, could only be alleviated by the formation of the interface pores. ${ }^{56}$ As shown in Fig. 6b, the EDX test confirmed the existence of silicon (Si) element in the PEN/SiO nanocomposite membranes, and quantitatively proved that the $\mathrm{SiO}_{2} \mathrm{NPs}$ contents on the membrane surface increased with the increase of the initial addition of nanoparticles.

AFM analysis was carried out to further investigate the surface topology and roughness of the membranes. Generally, membranes with a rougher surface were prone to fouling more easily as their surfaces had more bulges and valleys which provided deposition sites for foulants. ${ }^{57}$ Fig. 7 represented the surface 2D and 3D AFM images of the pristine PEN and nanocomposite membranes. High peak with brighter areas corresponded to nodule, while the pore or low valley was characterized by the dark regions. The surface roughness explained in terms of the root-mean-square roughness $\left(R_{\mathrm{q}}\right)$ and mean roughness $\left(R_{\mathrm{a}}\right)$ were listed in Table 2, The pristine PEN membrane had the smoothest surface, and the surface roughness increased with the increasing zwitterionic nano- $\mathrm{SiO}_{2}$ present on top layer. Moreover, with the agglomeration of nanoparticles became more obvious, the roughness of the membranes surface increased.

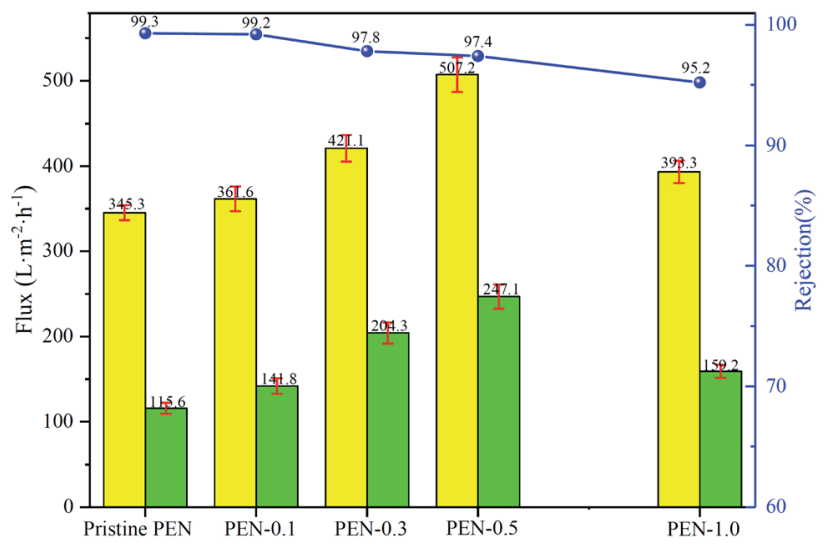

Fig. 8 Effect of zwitterionic nano- $\mathrm{SiO}_{2}$ content on Flux and BSA rejection. 


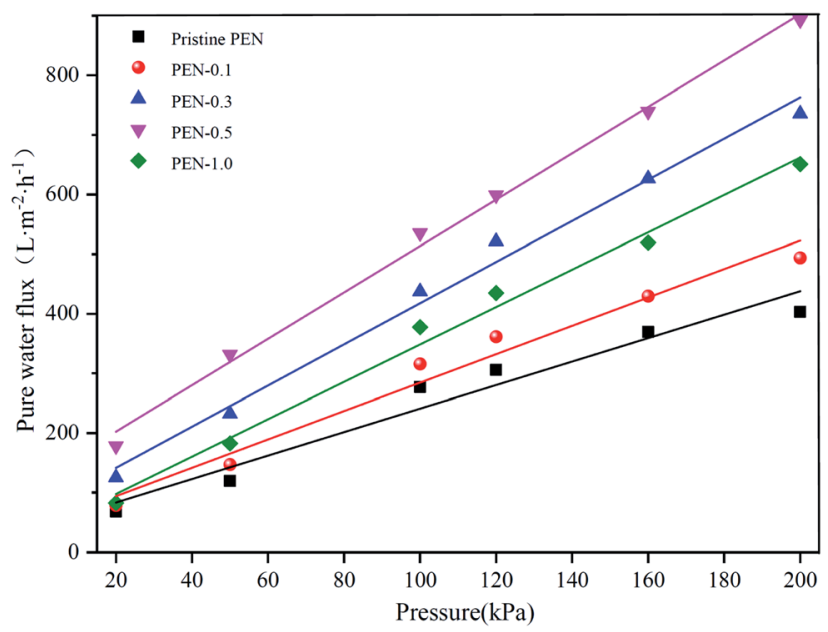

Fig. 9 Effect of zwitterionic nano- $\mathrm{SiO}_{2}$ content on membrane $P_{\mathrm{m}}$.

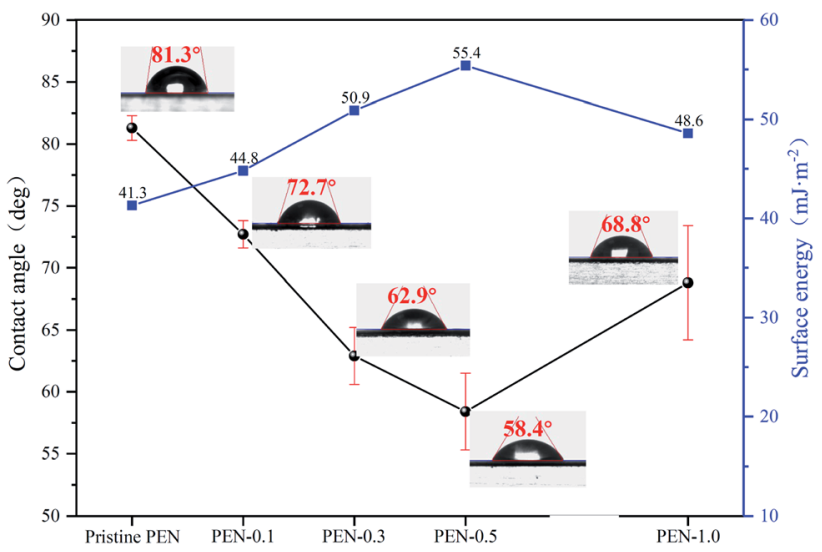

Fig. 10 Water contact angle and surface energy of pristine PEN and nanocomposite membranes.

EWC is an important parameter to reflect the ability of the membrane to hold moisture, which is related to $\varepsilon$ and mainly determined by the macrovoids in the membrane..$^{58}$ As shown in Table 2, the incorporation of zwitterionic nano-SiO ${ }_{2}$ in the polymeric membrane matrix promoted the increase of EWC, $\varepsilon$ and $r_{\mathrm{m}}$ for the nanocomposite membranes in comparison with pristine PEN membrane. When the zwitterionic nano- $\mathrm{SiO}_{2}$ content varied from 0 to $0.5 \mathrm{wt} \%$, the EWC, $\varepsilon$ and $r_{\mathrm{m}}$ of prepared membranes increased from 73.7 to $83.0 \%, 66.5$ to $76.1 \%$ and 42.4 to $52.1 \mathrm{~nm}$, respectively. The increase in porosity of the nanocomposite membranes could be attributed to two aspects. Firstly, the incorporation of zwitterionic nano- $\mathrm{SiO}_{2}$ could increase the thermodynamic instability of the casting solution which accelerated the exchange rate of solvent and non-solvent and promoted the formation of macrovoids during the phase inversion process; ${ }^{59,60}$ secondly, the presence of zwitterionic nano- $\mathrm{SiO}_{2}$ in polymer continuous phase of the nanocomposite membranes increased the structural heterogeneity of those membranes which leaded to the formation of more macrovoids to accommodate more water. ${ }^{61,62}$ However, with the further increase of zwitterionic nano- $\mathrm{SiO}_{2}$ content to $1 \mathrm{wt} \%$, the agglomeration of nanoparticles weakened its effect on the thermodynamic instability of the casting solution, and the slower exchange rate of solvent and non-solvent eventually leaded to the PEN-1.0 with reduced EWC, $\varepsilon$ and $r_{\mathrm{m}}$, respectively.

\subsection{Membrane separation performance}

Fig. 8 presents the PWF, permeation flux and BSA rejection ratio of prepared membrane. A trade-off between flux and selectivity of composite membranes have been found. With the addition of zwitterionic nano- $\mathrm{SiO}_{2}$ from 0 to $0.5 \mathrm{wt} \%$, the $\mathrm{PWF}$ and permeation flux of the prepared composite membrane gradually increased, while the corresponding BSA rejection ratio gradually decreased. This exactly coincided with the tendency of porosity and $r_{\mathrm{m}}$ of the composite membrane surface from small to large. These results demonstrated that the increase in porosity and $r_{\mathrm{m}}$ of composite membrane with $0-0.5 \mathrm{wt} \%$ zwitterionic nano- $\mathrm{SiO}_{2}$ content could attract water molecules inside the membrane matrix and promoted the passage of water molecules through the membrane to increase the permeability. ${ }^{63}$ However, further increasing zwitterionic nano- $\mathrm{SiO}_{2}$ content to $1 \mathrm{wt} \%$, both the flux and selectivity of prepared composite membrane decreased. This could be explained by the fact that the particle agglomeration caused by excessive addition of nanoparticles might cause the blockage of the membrane pores, and ultimately leaded to the reducing of separation performance. ${ }^{64}$ An optimal performance of PWF (507.2 $\left.\mathrm{L} \mathrm{m}^{-2} \mathrm{~h}^{-1}\right)$, permeation flux $\left(247.1 \mathrm{~L} \mathrm{~m}^{-2} \mathrm{~h}^{-1}\right)$ and BSA rejection ratio $(97.4 \%)$ was obtained when the addition of zwitterionic nano- $\mathrm{SiO}_{2}$ reached $0.5 \mathrm{wt} \%$.

The effect of the added zwitterionic nano-SiO ${ }_{2}$ content on $P_{\mathrm{m}}$ of the prepared nanocomposite membrane was shown in Fig. 9 and the specific $P_{\mathrm{m}}$ value was calculated by eqn (7). With the incorporation of zwitterionic nano- $\mathrm{SiO}_{2}$ increased from 0 to $0.5 \mathrm{wt} \%$, the $P_{\mathrm{m}}$ of the nanocomposite membrane increased from 1.97 to 3.89 , which mean the permeability enhanced with increasing the concentration of zwitterionic nano-SiO ${ }_{2}$. This improvement in permeability could be attributed to the higher

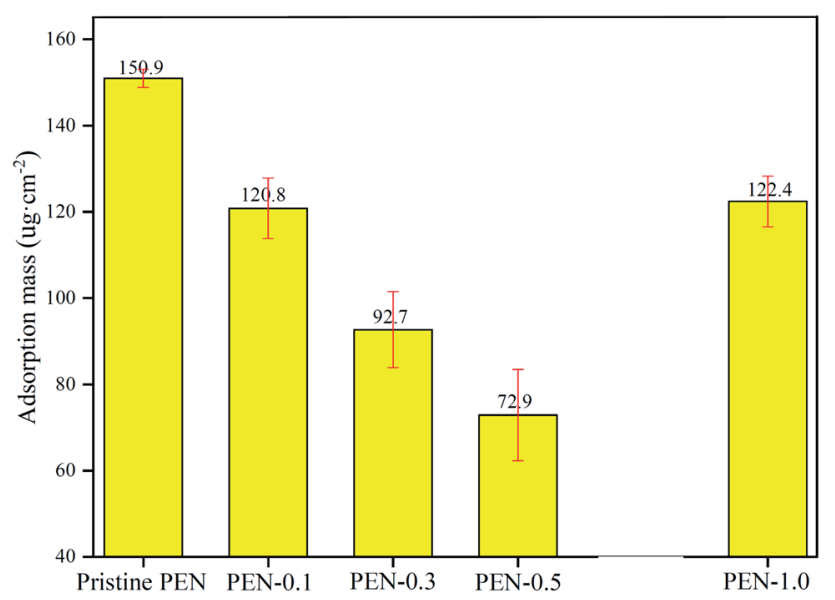

Fig. 11 Static adsorption of BSA solution of pristine PEN and nanocomposite membranes. 


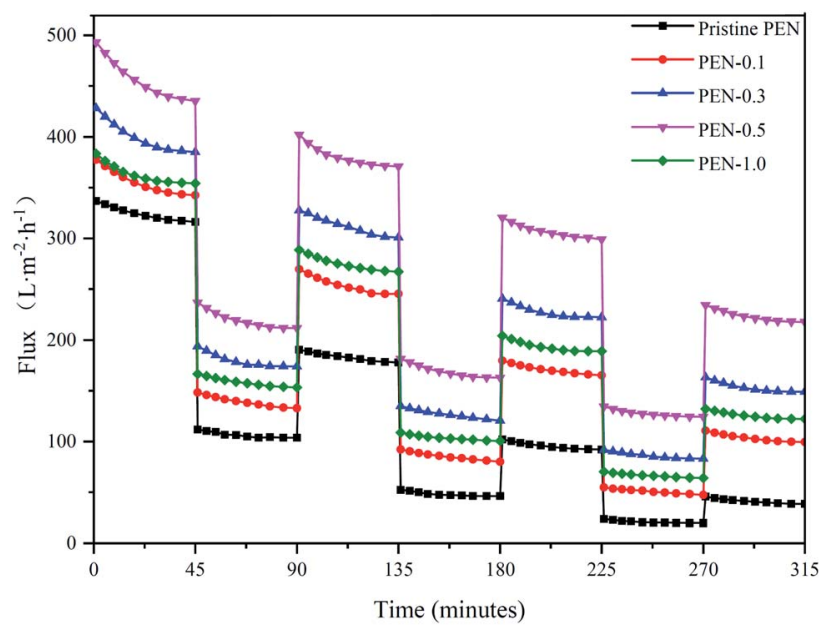

Fig. 12 Time-dependent fluctuation of pure water flux and BSA solution flux in three cycles.

porosity with addition of zwitterionic nano- $\mathrm{SiO}_{2}$ in the polymer matrix. When modified $\mathrm{SiO}_{2}$ nanoparticles content further increased to $1.0 \mathrm{wt} \%, P_{\mathrm{m}}$ decreased to 3.14 instead, which mean that an excessive filler content would lead to a particle agglomeration, blocking the membrane pores that prevented the passage of water flow. ${ }^{65,66}$

\subsection{Membrane hydrophilicity and anti-fouling performance}

The water contact angle (WCA) and surface energy $(\gamma)$ tests were used to evaluate the hydrophilicity and wettability of membranes. Generally, membranes with lower WCA or higher $\gamma$ have more hydrophilic membrane surfaces. ${ }^{67,68}$ Fig. 10 showed that pristine PEN had highest WCA of $81.3^{\circ}$ and lowest $\gamma$ of 41.3 $\mathrm{mJ} \mathrm{m}^{-2}$, while with the gradual addition of zwitterionic nano$\mathrm{SiO}_{2}$ to $0.5 \mathrm{wt} \%$, the WCA decreased to $58.4^{\circ}$ and $\gamma$ increased to $55.4 \mathrm{~mJ} \mathrm{~m}^{-2}$. This result indicated that the addition of zwitterionic nano- $\mathrm{SiO}_{2}$ effectively improved the hydrophilicity of nanocomposite membrane surface. Hydroxyl functional group rich in the $\mathrm{SiO}_{2}$ nanoparticle surface could bind more water molecules through hydrogen bonding, thereby increasing the wettability of the nanocomposite membrane. ${ }^{63}$ When the content of zwitterionic nano- $\mathrm{SiO}_{2}$ reached $1.0 \mathrm{wt} \%$, the uneven distribution of nanoparticles on membrane surface caused the hydrophilicity of PEN-1.0 decreased.

The static fouling adsorption experiment results of pristine and nanocomposite PEN membranes were shown in Fig. 11. All PEN MMMs modified with zwitterionic $\mathrm{SiO}_{2}$ NPs nanocomposites exhibited lower BSA adsorption capacity than pristine PEN membrane $\left(150.9 \mu \mathrm{g} \mathrm{cm} \mathrm{cm}^{-2}\right)$. The presence of zwitterionic $\mathrm{SiO}_{2}$ NPs on the surface of PEN nanocomposite membranes were beneficial to the formation of a tight hydration layer on the membrane surface, thereby further weakened the specific adsorption of BSA on the membrane surface. ${ }^{69} \mathrm{BSA}$ adsorption amount of PEN-0.5 was only $72.9 \mu \mathrm{g} \mathrm{cm} \mathrm{c}^{-2}$, which was the lowest among all PEN MMMs.

It is well known that membrane fouling will reduce the membrane permeability and shorten the usage time. ${ }^{70}$ The time dependent flux of pristine PEN and nanocomposite membranes were conducted to evaluate the effect of adding zwitterionic nano- $\mathrm{SiO}_{2}$ on antifouling performance, and the results were shown in Fig. 12. A significant flux drop occurred when the pure water feed was replaced by BSA solution due to larger size contaminants sticking to and blocking the pore of membrane surface. ${ }^{71}$ After the membrane was thoroughly washed and backwashed, the PWF was measured again in order to determine the restoration ability and contribution of $R_{\mathrm{r}}$ and $R_{\mathrm{ir}}$ in $R_{\mathrm{t}}$ of each membrane. The PWF of all membranes could not be fully recovered due to the irreversible fouling. ${ }^{72}$

As shown in Fig. 13a, the antifouling effect of nanocomposite membrane was significantly improved compared to pristine PEN. With the increase in modified nanoparticles content, the nanocomposite membranes had higher FRR, $R_{\mathrm{r}}$ and lower $R_{\mathrm{t}}$, $R_{\mathrm{ir}}$, especially PEN-0.5 has an FRR of up to $85.3 \%$. This could be explained as the content of hydroxyl groups on the membrane surface increased with the addition of zwitterions nano- $\mathrm{SiO}_{2}$, making it easier to bind water molecules through hydrogen bonding by forming a hydrated layer on the membrane surface and effectively inhibit the adhesion of BSA on the membrane surface to reduce the total pollution degree. ${ }^{73,74}$ Simultaneously, under the same cleaning conditions, the contamination of
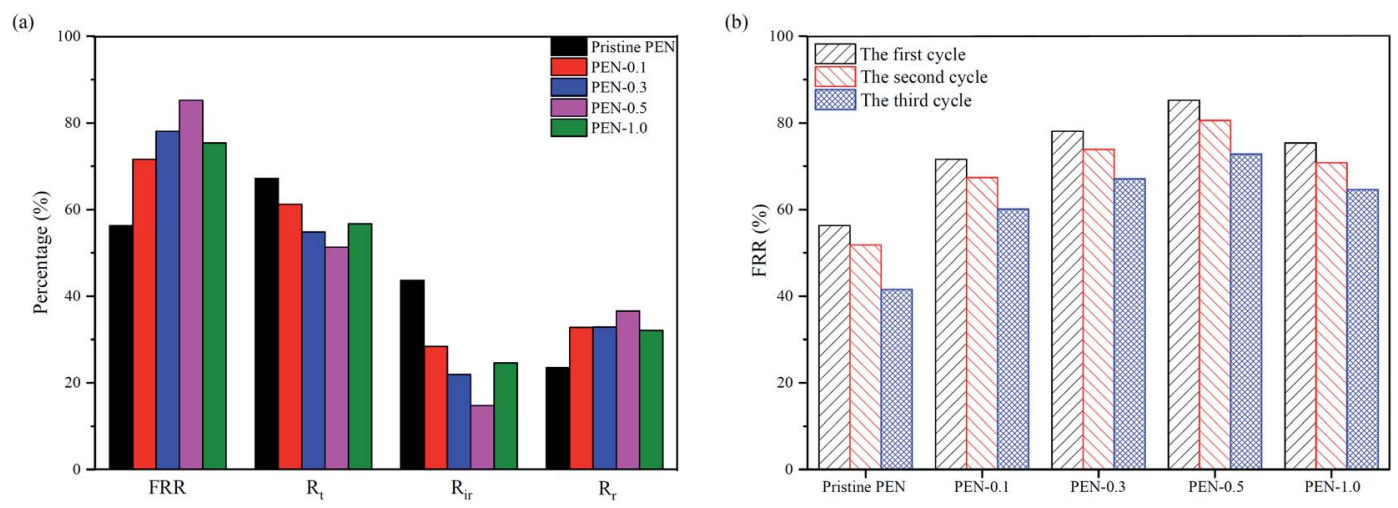

Fig. 13 (a) Anti-fouling parameters in the first cycle and (b) the FRR of the membranes in three cycles. 
Table 3 Pure water flux, BSA rejection ratio and FRR comparison of nanocomposite UF membranes

\begin{tabular}{|c|c|c|c|c|c|}
\hline Hybrid membrane & Operating pressure (bar) & $\operatorname{PWF}\left(\mathrm{L} \mathrm{m}^{-2} \mathrm{~h}^{-1}\right)$ & Rejection (\%) & FRR (\%) & Ref. \\
\hline $\mathrm{PVDF} / \mathrm{TiO}_{2}$ & 1 & 103.5 & 85.6 & 96.9 & Moghadam et al. $^{78}$ \\
\hline PES/PHEMA@SiO 2 & 2 & 141.7 & 95.0 & 84.4 & Zhu et al. ${ }^{79}$ \\
\hline PVDF-OMW-GO & 1 & 203 & 81.4 & 80.4 & Zhang et $a l .{ }^{81}$ \\
\hline $\mathrm{PSf} / \mathrm{SiO}_{2}-\mathrm{GO}$ & 1 & 375 & 98 & 72 & $\mathrm{Wu}$ et al. ${ }^{82}$ \\
\hline PES/HANTs-DA-TA & 1 & 439 & 97 & 77.9 & $\mathrm{Mu}$ et $a l^{55}$ \\
\hline
\end{tabular}

Table 4 Mechanical strength of pristine PEN and nanocomposite membranes

\begin{tabular}{lll}
\hline Membranes & $\begin{array}{l}\text { Breaking strength } \\
(\mathrm{mPa})\end{array}$ & Elongation at break (\%) \\
\hline Pristine PEN & $5.42 \pm 0.27$ & $23.60 \pm 1.50$ \\
PEN-0.1 & $6.03 \pm 0.15$ & $27.22 \pm 2.09$ \\
PEN-0.3 & $6.67 \pm 0.22$ & $28.74 \pm 1.95$ \\
PEN-0.5 & $5.60 \pm 0.12$ & $28.96 \pm 1.06$ \\
PEN-1.0 & $4.53 \pm 0.11$ & $20.38 \pm 0.42$ \\
\hline
\end{tabular}

membrane surface with hydrated layer was easier washed away and the FRR increased..$^{75}$ When the content of nanoparticles continued to increase to $1.0 \mathrm{wt} \%$, the hydrophobic modification effect was reduced due to the agglomeration of nanoparticles on the membrane surface. The pure water flux recovery under three cycles was shown in Fig. 13b. The FRR of all membranes showed a downward trend with increasing the cycles, namely $\mathrm{FRR}_{1 \mathrm{st}}>$ $\mathrm{FRR}_{2 \mathrm{st}}>\mathrm{FRR}_{3 \mathrm{st}}$. As the cycles increased, the interaction between the membrane surface protein and protein in the solution became stronger. The protein in the solution was more likely to directly interact with the membrane surface protein to deposit on the membrane surface. The total pollution degree of the membrane surface increased, the cleaning difficulty increased, and the flux recovery rate further decreased. ${ }^{76,77}$

As listed in Table 3, the overall performance of PEN hybrid membrane with optimum zwitterionic $\mathrm{SiO}_{2}$ NPs content (0.5 wt\%) was compared with other inorganic nanocomposite membranes published. The PEN-0.5 showed better performance in terms of pure water flux, rejection of BSA and flux recovery ratio. We think that zwitterionic $\mathrm{SiO}_{2} \mathrm{NPS}$ was a promising nanofiller used to prepared antifouling PEN ultrafiltration membranes.

\subsection{Membrane mechanical properties}

The mechanical strength of pressure driven UF membrane was crucial to ensure long-term stable operation under pressure. The mechanical performance parameters of pristine PEN and nanocomposite membranes were listed in Table 4. Compared with pristine PEN, when the addition of zwitterionic nanoparticles did not exceed $0.3 \mathrm{wt} \%$, the breaking strength of the prepared nanocomposite membranes were significantly improved, and the change of breaking elongation was small. The improved mechanical strength of nanocomposite membranes could be attributed to the both synergistic effect of the good dispersion stability of nano- $\mathrm{SiO}_{2}$ in the membrane matrix and the hydrogen bond between the hydroxyl group of silica surface and the PEN molecular chain as shown in Fig. 14. With further increasing nanoparticles content, the mechanical properties of nanocomposite membranes decreased significantly. This could be caused by the easier formation of stress concentration points in the membrane matrix under the action of external forces by the agglomeration of nanoparticles.

\section{Conclusions}

In this study, zwitterionic nano-SiO $\mathrm{S}_{2}$ was successfully prepared and used as filler to prepare $\mathrm{PEN} /$ zwitterionic nano-SiO ${ }_{2}$ composite membranes by immersion precipitation phase inversion method. The effect of zwitterionic nano-SiO ${ }_{2}$ addition amount on the structure and performance of PEN/zwitterionic nano-SiO ${ }_{2}$ composite membrane was studied. With the optimum addition amount of zwitterionic nano- $\mathrm{SiO}_{2}$ of $0.5 \mathrm{wt} \%$, the prepared $\mathrm{PEN} /$ zwitterionic nano-SiO ${ }_{2}$ composite membrane PEN-0.5 showed PWF of 507.2 $\mathrm{L} \mathrm{m}^{-2} \mathrm{~h}^{-1}$, permeation flux of $247.1 \mathrm{~L} \mathrm{~m}^{-2} \mathrm{~h}^{-1}$ and BSA rejection ratio of $97.4 \%$.

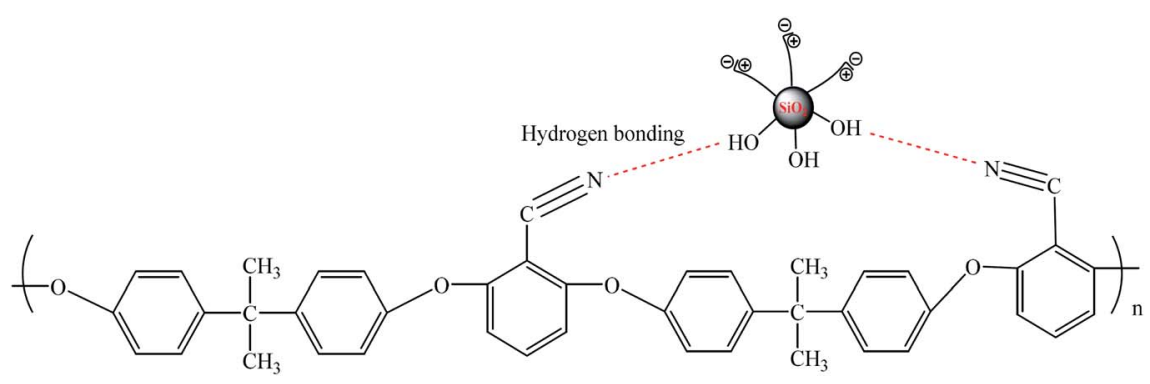

Fig. 14 The schematic diagram of the hydrogen bond interaction between zwitterionic $\mathrm{SiO}_{2} \mathrm{NPs}_{\text {and }} \mathrm{PEN}$ molecular chain. 
Compared with pristine PEN, the porosity, EWC of PEN-0.5 had been significantly improved, the WCA decreased from $81.3^{\circ}$ to $58.4^{\circ}$, meanwhile the surface energy increased from 41.3 to 55.4

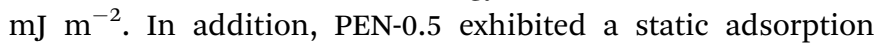
capacity of $72.9 \mu \mathrm{g} \mathrm{cm} \mathrm{cm}^{-2}$ which was less than half of pristine PEN, and the FRR under dynamic antifouling experiment was as high as $85.3 \%$. The excellent antifouling performance of PEN/ zwitterionic nano-SiO $\mathrm{S}_{2}$ nanocomposite membranes indicates that the blending modification with zwitterionic nano- $\mathrm{SiO}_{2}$ is an effective and convenient method to enhance the permeability and antifouling performance of PEN membranes.

\section{Conflicts of interest}

The authors declare that they have no known competing financial interests or personal relationships that could have appeared to influence the work reported in this paper.

\section{Acknowledgements}

This work was supported by Research Startup program of Donghua University (285-07-005702) and the Key-Area Research and Development Program of Guangdong Province (2020B010182002).

\section{References}

1 A. Barbetta, M. Dentini, E. M. Zannoni and M. E. D. Stefano, Tailoring the porosity and morphology of gelatinmethacrylate polyHIPE scaffolds for tissue engineering applications, Langmuir, 2005, 21(26), 12333-12341.

2 Y. Pan, Z. X. Yu, H. Shi, Q. Chen, G. Y. Zeng, H. H. Di, $\mathrm{X}$. Q. Ren and Y. He, A novel antifouling and antibacterial surface-functionalized PVDF ultrafiltration membrane via binding $\mathrm{Ag} / \mathrm{SiO}_{2}$ nanocomposites, J. Chem. Technol. Biotechnol., 2017, 92(3), 552-562.

$3 \mathrm{~W}$. Dan and M. R. Bird, The fouling and cleaning of ultrafiltration membranes during the filtration of model tea component solutions, J. Food Process Eng., 2007, 30(3), 293-323.

4 H. S. Thiam, W. R. W. Daud, S. K. Kamarudin, A. B. Mohammad, A. A. H. Kadhum, K. S. Loh and E. H. Majlan, Overview on nanostructured membrane in fuel cell applications, Int. J. Hydrogen Energy, 2011, 36(4), 3187-3205.

5 D. Song, J. Xu, Y. P. Fu, L. Xu and B. T. Shan, Polysulfone/ sulfonated polysulfone alloy membranes with an improved performance in processing mariculture wastewater, Chem. Eng. J., 2016, 304(11), 882-889.

6 B. E. Logan and M. Elimelech, Membrane-based processes for sustainable power generation using water, Nature, 2012, 488(7411), 313-319.

7 M. Ulbricht, Advanced functional polymer membranes, Polymer, 2006, 47(7), 2217-2262.

8 Z. Yi, L. P. Zhu, L. Cheng, B. K. Zhu and Y. Y. Xu, A readily modified polyethersulfone with amino-substituted groups: its amphiphilic copolymer synthesis and membrane application, Polymer, 2012, 52(2), 350-358.

9 W. Gao, H. Liang, J. Ma, M. Han, Z. L. Chen, Z. S. Han and G. B. Li, Membrane fouling control in ultrafiltration technology for drinking water production: a review, Desalination, 2011, 272(1-3), 1-8.

10 S. S. Kulkarni, E. W. Funk and N. N. Li, Introduction and Definitions. In: Membrane Handbook, Springer, 1992, DOI: 10.1007/978-1-4615-3548-5-26.

11 I. G. P. Syed, A. M. Isloor, Inamuddin, A. M. Asiri, A. F. Ismail, R. Kumar and M. I. Ahamed, Performance intensification of the polysulfone ultrafiltration membrane by blending with copolymer encompassing novel derivative of poly(styrene-co-maleic anhydride) for heavy metal removal from wastewater, Chem. Eng. J., 2018, 353(12), 425-435.

12 I. K. Moideen, A. M. Isloor, B. Garudachari and A. F. Ismail, The effect of glycine betaine additive on the PPSU/PSF ultrafiltration membrane performance, Desalin. Water Treat., 2016, 57(52), 24788-24798.

13 D. P. Liu, T. B. Wang and C. J. He, Antifouling polyethersulfone membrane blended with a dual-mode amphiphilic copolymer, J. Mater. Sci., 2016, 51(16), 73837394.

14 M. O. Mavukkandy, M. R. Bilad, A. Giwa, S. W. Hasan and H. A. Arafat, Leaching of PVP from PVDF/PVP blend membranes: impacts on membrane structure and fouling in membrane bioreactors, J. Mater. Sci., 2016, 51(9), 1-14.

15 G. G. Shi, Y. Q. Shen, P. Mu, Q. T. Wang, Y. X. Yang, S. Y. Ma and J. Li, Effective separation of surfactant-stabilized crude oil-in-water emulsions by using waste brick powder-coated membranes under corrosive conditions, Green Chem., 2020, 22(4), 1345-1352.

16 H. J. Zhang, Y. Q. Shen, M. J. Li, G. R. Zhu, H. Feng and J. Li, Egg shell powders-coated membrane for surfactantstabilized crude oil-in-water emulsions efficient separation, ACS Sustainable Chem. Eng., 2019, 7(12), 10880-10887.

17 C. Li, S. X. Li, L. Lv, B. W. Su and M. Z. Hu, High solventresistant and integrally crosslinked polyimide-based composite membranes for organic solvent nanofiltration, $J$. Membr. Sci., 2018, 564, 10-21.

$18 \mathrm{M}$. Hossein and B. Rafie, Cellulose acetate/SiO $\mathrm{S}_{2}-\operatorname{poly}(2-$ acrylamido-2-methylpropane sulfonic acid) hybrid nanofiltration membrane: application in removal of ceftriaxone sodium, J. Iran. Chem. Soc., 2018, 15(12), 28392849.

19 H. Y. Li, P. Mu, J. Li and Q. Wang, Inverse desert beetle-like ZIF-8/PAN composite nanofibrous membrane for highly efficient separation of oil-in-water emulsions, J. Mater. Chem. A, 2021, 9(7), 4167-4175.

20 V. L. Rao, A. Saxena and K. N. Ninan, Poly(arylene ether nitrile) (PEN), J. Macromol. Sci., Polym. Rev., 2002, 42(4), 513-540.

21 Y. Q. Zhao, Y. J. Lei, F. B. Meng, J. C. Zhong, R. Zhao and X. B. Liu, Electrical, thermal, and mechanical properties of polyarylene ether nitriles/graphite nanosheets 
nanocomposites prepared by masterbatch route, J. Mater. Sci., 2011, 46(3), 824-831.

22 Y. You, S. N. Liu, L. Tu, Y. J. Wang, C. H. Zhan, X. Y. Du, R. B. Wei and X. B. Liu, Controllable fabrication of poly(arylene ether nitrile) dielectrics for thermal-resistant film capacitors, Macromolecules, 2019, 52(15), 5850-5859.

23 Y. Q. Zhan, S. J. He, X. Y. Wan, S. M. Zhao and Y. L. Bai, Thermally and chemically stable poly(arylene ether nitrile)/ halloysite nanotubes intercalated graphene oxide nanofibrous composite membranes for highly efficient oil/ water emulsion separation in harsh environment, $J$. Membr. Sci., 2018, 567, 76-88.

24 W. L. Zhang, Z. J. Wang and X. B. Liu, A novel poly(arylene ether nitrile) ultrafiltration membrane for water purification and its antifouling property with in situgenerated $\mathrm{SiO}_{2}$ nanoparticles, High Perform. Polym., 2019, 31(8), 977-985.

25 W. Gao, H. Liang, J. Ma, H. Mei, Z. L. Chen, Z. S. Han and G. B. Li, Membrane fouling control in ultrafiltration technology for drinking water production: a review, Desalination, 2011, 272(1-3), 1-8.

26 I. Banerjee, R. C. Pangule and R. S. Kane, Antifouling Coatings: Recent Developments in the Design of Surfaces That Prevent Fouling by Proteins, Bacteria, and Marine Organisms, Adv. Mater., 2011, 23(6), 690-718.

27 L. Braeken, B. Bettens, K. Boussu, P. V. D. Meeren, J. Cocquyt, J. Vermant and B. V. D. Bruggen, Transport mechanisms of dissolved organic compounds in aqueous solution during nanofiltration, J. Membr. Sci., 2006, 279(12), 311-319.

28 A. K. Wardani, D. Ariono, Subagjo and I. G. Wenten, Hydrophilic modification of polypropylene ultrafiltration membrane by air-assisted polydopamine coating, Polym. Adv. Technol., 2019, 30(4), 1148-1155.

29 H. G. Sun, X. B. Yang, Y. Q. Zhang, X. Q. Cheng, Y. C. Xu, Y. P. Bai and L. Shao, Segregation-induced in situ hydrophilic modification of poly(vinylidene fluoride) ultrafiltration membranes via sticky poly(ethylene glycol) blending, J. Membr. Sci., 2018, 563, 22-30.

30 A. F. Ismail, C. S. Ong, N. Misdan and W. J. Lau, Nanomaterials for biofouling and scaling mitigation of thin film composite membrane: a review, Desalination, 2016, 393(SI), 2-5.

31 H. X. Yu, L. Gu, S. F. Wu, G. X. Dong, X. B. Qiao, K. Zhang, X. Y. Lu, H. F. Wen and D. F. Zhang, Hydrothermal carbon nanospheres assisted-fabrication of PVDF ultrafiltration membranes with improved hydrophilicity and antifouling performance, Sep. Purif. Technol., 2020, 247, 116889.

32 A. V. R. Reddy, D. J. Mohan, A. Bhattacharya, V. J. Shah and P. K. Ghosh, Surface modification of ultrafiltration membranes by preadsorption of a negatively charged polymer I. Permeation of water soluble polymers and inorganic salt solutions and fouling resistance properties, J. Membr. Sci., 2003, 214(2), 211-221.

33 H. Y. Yu, Z. K. Xu, Y. J. Xie, Z. M. Liu and S. Y. Wang, Flux enhancement for polypropylene microporous membrane in a SMBR by the immobilization of poly( $N$-vinyl-2- pyrrolidone) on the membrane surface, J. Membr. Sci., 2006, 279(1-2), 148-155.

34 Y. Liu, S. L. Zhang and G. B. Wang, The preparation of antifouling ultrafiltration membrane by surface grafting zwitterionic polymer onto poly(arylene ether sulfone) containing hydroxyl groups membrane, Desalination, 2013, 316, 127-136.

35 R. K. Du, B. J. Gao and Y. B. Li, Hydrophilic polysulfone film prepared from polyethylene glycol monomethylether via coupling graft, Appl. Surf. Sci., 2013, 274(1), 288-294.

36 S. L. Yu, X. T. Zuo, R. L. Bao, X. Xu, J. Wang and J. Xu, Effect of $\mathrm{SiO}_{2}$ nanoparticle addition on the characteristics of a new organic-inorganic hybrid membrane, Polymer, 2009, 50(2), 553-559.

37 M. Obaid, G. M. K. Tolba, M. Motlak, O. A. Fadali, K. A. Khalil, A. A. Almajid, B. Kim and N. A. M. Barakat, Effective polysulfone-amorphous $\mathrm{SiO}_{2}$ NPs electrospun nanofiber membrane for high flux oil/water separation, Chem. Eng. J., 2015, 279, 631-638.

38 M. Parimalam, M. R. Islam and R. M. Yunus, Effects of nanosilica and titanium oxide on the performance of epoxy-amine nanocoatings, J. Appl. Polym. Sci., 2019, 136(35), 47901.

39 J. H. So, S. M. Yang, C. Y. Kim and J. C. Hyun, Microstructure and rheological behaviour of electrosterically stabilized silica particle suspensions, Colloids Surf., A, 2001, 190(1-2), 89-98.

40 A. B. Lowe and C. L. Mccormick, Synthesis and solution properties of zwitterionic polymers, Chem. Rev., 2002, 102(11), 4177-4189.

41 A. Islam, J. G. Li, M. Pervaiz, Z. H. Lu, M. Sain, L. H. Chen and X. H. Ouyang, Zwitterions for Organic/Perovskite Solar Cells, Light-Emitting Devices, and Lithium Ion Batteries: Recent Progress and Perspectives, Adv. Energy Mater., 2019, 9, 1803354.

42 J. Zhao, M. Milanova, M. M. C. G. Warmoeskerken and V. Dutschk, Surface modification of $\mathrm{TiO}_{2}$ nanoparticles with silane coupling agents, Colloids Surf., A, 2012, 413, 273-279.

43 X. G. Li, Y. Q. He and M. T. Swihart, Surface functionalization of silicon nanoparticles produced by laser-driven pyrolysis of silane followed by $\mathrm{HF}^{-\mathrm{HNO}_{3}}$ etching, Langmuir, 2004, 20(11), 4720-4727.

44 J. Zhao, M. Milanova, M. M. C. G. Warmoeskerken and V. Dutschk, Surface modification of $\mathrm{TiO}_{2}$ nanoparticles with silane coupling agents, Colloids Surf., A, 2012, 413, 273-279.

$45 \mathrm{X}$. G. Li, Y. Q. He and M. T. Swihart, Surface functionalization of silicon nanoparticles produced by laser-driven pyrolysis of silane followed by $\mathrm{HF}^{-\mathrm{HNO}_{3}}$ etching, Langmuir, 2004, 20(11), 4720-4727.

46 R. C. Su, W. F. Li, J. Peng and D. Jun, Surface modification of nano-sized $\mathrm{SiO}_{2}$ with silane coupling agent and its dispersion, Chem. Ind. Eng. Prog., 2009, 28(9), 1596-1603.

47 L. Y. Jiang, C. M. Leu and H. K. Wei, Layered silicates/ fluorinated polyimide nanocomposites for advanced 
dielectric materials applications, Adv. Mater., 2002, 14(6), 426-429.

48 Y. X. Zhang, Y. L. Liu, B. Q. Ren, D. Zhang and J. Zheng, Fundamentals and applications of zwitterionic antifouling polymers, J. Phys. D: Appl. Phys., 2019, 52, 403001.

$49 \mathrm{~J}$. Zhu, X. Z. Zhao and C. J. He, Zwitterionic $\mathrm{SiO}_{2}$ nanoparticles as novel additives to improve the antifouling properties of PVDF membranes, RSC Adv., 2015, 5(66), 53653-53659.

50 H. Tang, J. Yang, J. Zhong, R. Zhao and X. Liu, Synthesis and dielectric properties of polyarylene ether nitriles with high thermal stability and high mechanical strength, Mater. Lett., 2011, 65(17-18), 2758-2761.

51 J. T. Mao, H. P. Yang, Z. Gao, R. C. Zhang and S. Q. Chai, Study on photacatalysis and separation performance of KH550- $\mathrm{TiO}_{2}$ immobilized on PES ultrafiltration membrane, Environ. Sci. Technol., 2018, 31(4), 7-13.

52 Y. N. Yang, W. Jun, Q. Z. Zheng, X. S. Chen and H. X. Zhang, The research of rheology and thermodynamics of organicinorganic hybrid membrane during the membrane formation, J. Membr. Sci., 2008, 311(1-2), 200-207.

53 Y. N. Yang, H. X. Zhang, P. Wang, Q. Z. Zheng and J. Li, The influence of nano-sized $\mathrm{TiO}_{2}$ fillers on the morphologies and properties of PSF UF membrane, J. Membr. Sci., 2007, 288(12), 231-238.

54 W. Z. Lang, Q. Ji, J. P. Shen, Y. J. Guo and L. F. Chu, Modified poly(vinylidene fluoride) hollow fiber composite membranes reinforced by hydroxyapatite nanocrystal whiskers, J. Appl. Polym. Sci., 2013, 127(6), 4564-4572.

55 Y. F. Mu, K. Zhu, J. S. Luan, S. L. Zhang, C. Y. Zhang, R. Q. Na, Y. C. Yang, X. Zhang and G. B. Wang, Fabrication of hybrid ultrafiltration membranes with improved water separation properties by incorporating environmentally friendly taurine modified hydroxyapatite nanotubes, $J$. Membr. Sci., 2019, 577, 274-284.

56 M. L. Luo, J. Q. Zhao, W. Tang and C. S. Pu, Hydrophilic modification of poly(ether sulfone) ultrafiltration membrane surface by self-assembly of $\mathrm{TiO}_{2}$ nanoparticles, Appl. Surf. Sci., 2005, 249(1-4), 76-84.

57 Manorma, I. Ferreira, P. Alves, M. H. Gil and L. M. G. Ferreira, Lignin separation from black liquor by mixed matrix polysulfone nanofiltration membrane filled with multiwalled carbon nanotubes, Sep. Purif. Technol., 2021, 260, 118231.

58 B. Chakrabarty, A. K. Ghoshal and M. K. Purkait, Effect of molecular weight of PEG on membrane morphology and transport properties, J. Membr. Sci., 2008, 309(1-2), 209-221.

59 J. Q. Zhao, H. R. Han, Q. Q. Wang, C. Y. Yan, Y. Li, J. Yang, X. Feng, N. Yang, Y. P. Zhao and L. Chen, Hydrophilic and anti-fouling PVDF blend ultrafiltration membranes using polyacryloylmorpholine-based triblock copolymers as amphiphilic modifiers, React. Funct. Polym., 2019, 139(1), 92-101.

60 J. Q. Zhao, Q. Q. Wang, J. Yang, Y. Li, Z. Y. Liu, L. Q. Zhang, Y. P. Zhao, S. X. Zhang and L. Chen, Comb-shaped amphiphilic triblock copolymers blend PVDF membranes overcome the permeability-selectivity trade-off for protein separation, Sep. Purif. Technol., 2020, 239, 116596.

61 P. Daraei, S. S. Madaeni, N. Ghaemi, E. Salehi, M. A. Khadivi, R. Moradian and B. Astinchap, Novel polyethersulfone nanocomposite membrane prepared by $\mathrm{PANI} / \mathrm{Fe}_{3} \mathrm{O}_{4}$ nanoparticles with enhanced performance for $\mathrm{Cu}(\mathrm{ii})$ removal from water, J. Membr. Sci., 2012, 415, 250-259.

62 E. Bagheripour, A. R. Moghadassi, S. M. Hosseini, M. B. Ray, F. Parvizian and B. V. D. Bruggen, Highly hydrophilic and antifouling nanofiltration membrane incorporated with water-dispersible composite activated carbon/chitosan nanoparticles, Chem. Eng. Res. Des., 2018, 132, 812-821.

63 A. L. Ohland, V. M. M. Salim and C. P. Borges, Nanocomposite membranes for osmotic processes: incorporation of functionalized hydroxyapatite in porous substrate and in selective layer, Desalination, 2019, 463, 23-31.

64 H. Rabiee, V. Vatanpour, M. H. D. A. Farahani and H. Zarrabi, Improvement in flux and antifouling properties of PVC ultrafiltration membranes by incorporation of zinc oxide (ZnO) nanoparticles, Sep. Purif. Technol., 2015, 156, 299-310.

65 L. Wang, X. J. Song, T. Wang, S. Z. Wang, Z. Wang and C. J. Gao, Fabrication and characterization of polyethersulfone/carbon nanotubes (PES/CNTs) based mixed matrix membranes (MMMs) for nanofiltration application, Appl. Surf. Sci., 2015, 330, 118-125.

66 J. H. Choi, J. Jegal and W. N. Kim, Fabrication and characterization of multi-walled carbon nanotubes/polymer blend membranes, J. Membr. Sci., 2006, 284(1-2), 406-415.

67 Y. Q. Zhang and P. L. Liu, Polysulfone(PSF) composite membrane with micro-reaction locations (MRLs) made by doping sulfated $\mathrm{TiO}_{2}$ deposited on $\mathrm{SiO}_{2}$ nanotubes (STSNs) for cleaning wastewater, J. Membr. Sci., 2015, 493, 275-284.

68 S. J. Yang, Q. F. Zou, T. H. Wang and L. P. Zhang, Effects of GO and MOF@GO on the permeation and antifouling properties of cellulose acetate ultrafiltration membrane, $J$. Membr. Sci., 2019, 569, 48-59.

69 L. M. Bai, H. Y. Wu, J. W. Ding, A. Ding, X. Y. Zhang, N. Q. Ren, G. B. Li and H. Liang, Cellulose nanocrystalblended polyethersulfone membranes for enhanced removal of natural organic matter and alleviation of membrane fouling, Chem. Eng. J., 2020, 382, 122919.

70 A. Asatekin, S. Kang, M. Elimelech and A. M. Mayes, Antifouling ultrafiltration membranes containing polyacrylonitrile-graft-poly(ethylene oxide) comb copolymer additives, J. Membr. Sci., 2007, 298(1-2), 136-146.

71 Z. X. Liu, Z. M. Mi, C. H. Chen, H. W. Zhou, X. G. Zhao and D. M. Wang, Preparation of hydrophilic and antifouling polysulfone ultrafiltration membrane derived from phenolphthalin by copolymerization method, Appl. Surf. Sci., 2017, 401, 69-78.

72 M. Pirsaheb, M. H. D. A. Farahani, S. Zinadini, A. A. Zinatizadeh, M. Rahimi and V. Vatanpour, Fabrication of high-performance antibiofouling ultrafiltration membranes with potential application in membrane bioreactors (MBRs) comprising 
polyethersulfone (PES) and polycitrate-Alumoxane (PC-A), Sep. Purif. Technol., 2019, 211, 618-627.

73 H. G. Sun, X. B. Yang, Y. Q. Zhang, X. Q. Cheng, Y. C. Xu, Y. P. Bai and L. Shao, Segregation-induced in situ hydrophilic modification of poly(vinylidene fluoride) ultrafiltration membranes via sticky poly(ethylene glycol) blending, J. Membr. Sci., 2018, 563, 22-30.

74 J. R. Werber, C. O. Osuji and M. Elimelech, Materials for next-generation desalination and water purification membranes, Nat. Rev. Mater., 2016, 1(5), 18-22.

75 Y. F. Mu, H. Feng, S. L. Zhang, C. Y. Zhang, N. Lu, J. S. Luan and G. B. Wang, Development of highly permeable and antifouling ultrafiltration membranes based on the synergistic effect of carboxylated polysulfone and bioinspired co-deposition modified hydroxyapatite nanotubes, J. Colloid Interface Sci., 2020, 572, 48-61.

76 M. S. S. A. Saraswathi, D. Rana, K. Divya, S. Alwarappan and A. Nagendran, Fabrication of anti-fouling PVDF nanocomposite membranes using manganese dioxide nanospheres with tailored morphology, hydrophilicity and permeation, New J. Chem., 2018, 42(19), 15803-15810.

77 M. Padaki, D. Emadzadeh, T. Masturra and A. F. Ismail, Antifouling properties of novel PSf and TNT composite membrane and study of effect of the flow direction on membrane washing, Desalination, 2015, 362, 141-150.

78 M. T. Moghadam, G. Lesage, T. Mohammadi, J. P. Mericq, J. Mendret, M. Heran, C. Faur, S. Brosillon, M. Hemmati and F. Naeimpoor, Improved antifouling properties of $\mathrm{TiO}_{2} / \mathrm{PVDF}$ nanocomposite membranes in UV-coupled ultrafiltration, J. Appl. Polym. Sci., 2015, 132(21), 41731.

79 L. J. Zhu, L. P. Zhu, J. H. Jiang, Z. Yi, Y. F. Zhao, B. K. Zhu and Y. Y. Xu, Hydrophilic and anti-fouling polyethersulfone ultrafiltration membranes with poly(2-hydroxyethyl methacrylate) grafted silica nanoparticles as additive, $J$. Membr. Sci., 2014, 451, 157-168.

80 A. Khan, T. A. Sherazi, Y. Khan, S. H. Li, S. A. R. Naqvi and Z. Cui, Fabrication and characterization of polysulfone/ modified nanocarbon black composite antifouling ultrafiltration membranes, J. Membr. Sci., 2018, 554, 71-82.

81 J. G. Zhang, Z. W. Xu, W. Mai, C. Y. Min, B. M. Zhou, M. J. Shan, Y. L. Li, C. Y. Yang, Z. Wang and X. M. Qian, Improved hydrophilicity, permeability, antifouling and mechanical performance of PVDF composite ultrafiltration membranes tailored by oxidized low-dimensional carbon nanomaterials, J. Mater. Chem. A, 2013, 1(9), 3101-3111.

82 H. Q. Wu, B. B. Tang and P. Y. Wu, Development of novel $\mathrm{SiO}_{2}$-GO nanohybrid/polysulfone membrane with enhanced performance, J. Membr. Sci., 2014, 451, 94-102.

83 H. Q. Wu, Y. J. Liu, L. Mao, C. H. Jiang, J. M. Ang and X. H. Lu, Doping polysulfone ultrafiltration membrane with $\mathrm{TiO}_{2}$-PDA nanohybrid for simultaneous self-cleaning and self-protection, J. Membr. Sci., 2017, 532, 20-29. 